\title{
Color Developing Capacity of Plasma-treated Water as a Source of Nitrite for Meat Curing
}

\author{
Samooel Jung ${ }^{1}$, Hyun Joo Kim², Sanghoo Park ${ }^{3}$, Hae In Yong, Jun Ho Choe ${ }^{4}$, \\ Hee-Joon Jeon ${ }^{4}$, Wonho $\mathrm{Choe}^{3}$, and Cheorun Jo* \\ Department of Agricultural Biotechnology, Center for Food and Bioconvergence, and Research Institute \\ for Agriculture and Life Science, Seoul National University, Seoul 08826, Korea \\ ${ }^{1}$ Department of Animal Science and Biotechnology, Chungnam National University, Daejeon 34134, Korea \\ ${ }^{2}$ National Institute of Crop Science, RDA, Suwon 16616, Korea \\ ${ }^{3}$ Department of Physics, Korea Advanced Institute of Science and Technology, Daejeon 34141, Korea \\ ${ }^{4}$ Meat Processing Division, Lotte R\&D Center, Seoul 07209, Korea
}

\begin{abstract}
The interaction of plasma with liquid generates nitrogen species including nitrite $\left(\mathrm{NO}_{2}^{-}\right)$. Therefore, the color developing capacity of plasma-treated water (PTW) as a nitrite source for meat curing was investigated in this study. PTW, which is generated by surface dielectric barrier discharge in air, and the increase of plasma treatment time resulted in increase of nitrite concentration in PTW. The PTW used in this study contains $46 \mathrm{ppm}$ nitrite after plasma treatment for $30 \mathrm{~min}$. To evaluate the effect of PTW on the cured meat color, meat batters were prepared under three different conditions (control, non-cured meat batter; PTW, meat batter cured with PTW; Sodium nitrite, meat batter cured with sodium nitrite). The meat batters were vacuum-packaged and cooked in a water-bath at $80^{\circ} \mathrm{C}$ for $30 \mathrm{~min}$. The typical color of cured meat developed in cooked meat batter treated with sodium nitrite or PTW. The lightness $\left(L^{*}\right)$ and yellowness $\left(b^{*}\right)$ values were similar in all conditions, whereas, the redness $\left(a^{*}\right)$ values of cooked meat batter with PTW and sodium nitrite $(p<0.05)$ were significantly higher than the control. These data indicate that PTW can be used as a nitrite source in the curing process of meat without addition of other nitrite sources.
\end{abstract}

Keywords: atmospheric-pressure plasma, nitrite, cured color, meat batter

Received May 26, 2015; Revised September 16, 2015; Accepted October 7, 2015

\section{Introduction}

Nitrite $\left(\mathrm{NO}_{2}^{-}\right)$is commonly used in the curing of meat to develop cured color and flavor, and to inhibit lipid oxidation and spoilage due to microorganisms including Clostridium botulinum (Pegg and Shahidi, 2000). Sodium nitrite has been conventionally used as a nitrite source in manufacture of cured meat products, because it is an inexpensive and easy method. However, with increasing negative views of synthetic food additives lately, most consumers prefer meat cured with natural substances rather than chemical compounds such as sodium nitrite (Sebranek and Bacus, 2007). The use of vegetable juices

\footnotetext{
*Corresponding author: Cheorun Jo, Department of Agricultural Biotechnology, Center for Food and Bioconvergence, and Research Institute for Agriculture and Life Science, Seoul National University, Seoul 08826, Korea. Tel: +82-2-880-4804, Fax:+82-2-873-2271, E-mail: cheorun@snu.ac.kr
}

or concentrates containing nitrate or nitrite is a generally accepted alternative for sodium nitrite in processed meat industries (Sebranek et al., 2012). However, the use of vegetable juices or concentrates has a few disadvantages; their inherent flavors and pigments can develop unpleasant flavor and color in the cured meat products (Sindelar et al., 2007). Moreover, the use of vegetable juices or concentrates in curing meat often results in an increased cost of the product owing to the incorporation of their high cost and additional processes such as an incubation step, which are required for converting nitrate to nitrite (Horsch et al., 2014).

Plasma is an ionized gas with charged particles (Bogaerts et al., 2002). Plasma treatment technologies using atmospheric-pressure plasmas have widely been used for the sterilization of food or medical instruments, and surface modifications of dielectric or metallic materials (Bogaerts et al., 2002; Song et al., 2009; Yong et al., 2015). Water can also be purified through plasma treatment to

(9)This is an open access article distributed under the terms of the Creative Commons Attribution Non-Commercial License (http://creativecommons.org/licences/ by-nc/3.0) which permits unrestricted non-commercial use, distribution, and reproduction in any medium, provided the original wokr is properly cited. 
remove harmful contaminants including microorganisms (Foster et al., 2012). Oehmigen et al. (2010) reported that the interaction of plasma with liquid resulted in the generation of nitrogen species such as nitrate $\left(\mathrm{NO}_{3}^{-}\right)$and nitrite $\left(\mathrm{NO}_{2}^{-}\right)$as well as reactive oxygen species. Therefore, we hypothesized that the nitrite formed in plasma-treated water can be used in curing of meat products.

The objective of this study is to investigate the nitrite concentration in plasma-treated water (PTW) and the color change of meat batter treated with PTW, after cooking.

\section{Materials and Methods}

\section{Plasma treatment system}

As schematically illustrated in Fig. 1(A), a plasma device consisting of a powered electrode, ground electrode, and a $0.6 \mathrm{~mm}$ thick $\mathrm{Al}_{2} \mathrm{O}_{3}$ plate placed between electrodes, was used for generating surface dielectric barrier discharge (SDBD). To prevent oxidation of the metallic electrode due to high levels of oxidant species, the ground electrode, directly exposed to the plasma was made of nickel-chromium alloy. The ground electrode was perforated with rounded squares $(3 \times 3 \mathrm{~mm}$ in size $)$. The high voltage of bipolar square waveform with $15 \mathrm{kHz}$ frequency was applied to the powered electrode. The average power was $3.14 \mathrm{~W}$ and the peak power was $200 \mathrm{~W}$. To produce PTW, $100 \mathrm{~mL}$ of distilled water was exposed to SDBD in atmospheric air as seen in Fig. 1(A).

\section{Quantification of nitrite concentration}

Because the non-negligible amounts of nitric acid $\left(p K_{a}\right.$ $=-1.4)$ and nitrous acid $\left(p K_{a}=2.8-3.2\right)$ which release $\mathrm{H}^{+}$ ions are constantly formed in PTW, $\mathrm{pH}$ of PTW drops from 7 to 2-3. Thus, nitrite and nitrous acid coexist in PTW. The concentrations of nitrite and nitrous acid produced in PTW were estimated using UV-Vis absorption (MAYA
2000 Pro, Ocean optics Inc., USA). The absorption coefficients of nitrite and nitrous acid were adopted from Riordan et al. (2005). The concentrations of nitrite and nitrous acid were quantified from the absorption spectra in the wavelength range of 300-400 nm, as shown in Fig. 1(B).

\section{Manufacture of meat batter}

Pork hind leg meat and back fat were obtained from a commercial butcher (Korea). Visible fat and connective tissue was trimmed off and the meat was ground in a grinder with $6 \mathrm{~mm}$ plate. Ground meat was mixed with the back fat, cold water, and additives based on the type of treatment, as mentioned in Table 1 (control, non-cured meat batter; PTW, meat batter cured with PTW; Sodium nitrite, meat batter cured with sodium nitrite). Meat batter was vacuum-packaged in low-density polyethylene/nylon vacuum bags $(10 \times 10 \mathrm{~cm}$, oxygen permeability of 22.5 $\mathrm{mL} / \mathrm{m}^{2} / 24 \mathrm{~h}$ atm at $60 \% \mathrm{RH} / 25^{\circ} \mathrm{C}$, water vapor permeability of $4.7 \mathrm{~g} / \mathrm{m}^{2} / 24 \mathrm{~h}$ at $100 \% \mathrm{RH} / 25^{\circ} \mathrm{C}$ ) using a vacuum-packaging machine (FJ-600XL; Hankook Fujee Industries Co., Korea) at $650 \mathrm{mmHg}$. The meat was then cooked in a water-bath at $80^{\circ} \mathrm{C}$ for $30 \mathrm{~min}$, until internal temperature of cooked meat batter reached $75^{\circ} \mathrm{C}$.

Table 1. Formulations for manufacturing meat batter $(\mathrm{g})$

\begin{tabular}{cccc}
\hline \hline Ingredient & Control $^{1}$ & $\begin{array}{c}\text { Sodium } \\
\text { nitrite }\end{array}$ & PTW \\
\hline Pork hind leg meat & 600 & 600 & 600 \\
Pork back fat & 200 & 200 & 200 \\
Ice water & 200 & 200 & - \\
PTW & - & - & 200 \\
Sodium chloride & 12 & 12 & 12 \\
Sodium pyrophosphate & 2 & 2 & 2 \\
L-ascorbic acid & 0.5 & 0.5 & 0.5 \\
Sodium nitrite & - & 0.1 & - \\
\hline
\end{tabular}

${ }^{1}$ Control, non-cured meat batter; Sodium nitrite, meat batter cured with sodium nitrite; PTW, meat batter cured with plasma-treated water.

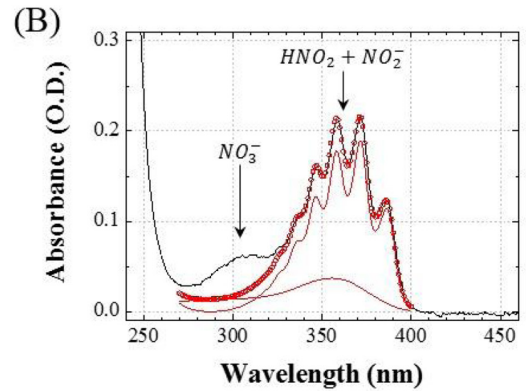

Fig. 1. (A) Schematic drawing of SDBD system and (B) a measured absorption spectrum (black solid line) of plasma-treated water (PTW) and fitting curves; red solid lines for nitrite and nitrous acid and red open symbol for their cumulative curve.

(A)

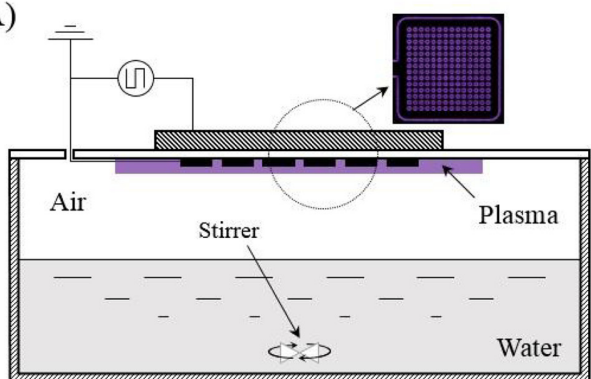



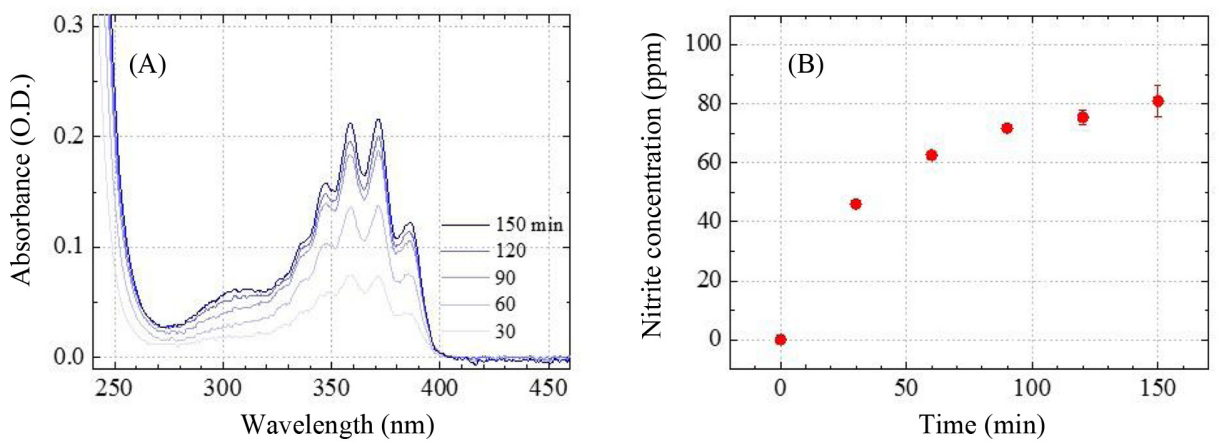

Fig. 2. (A) Absorption spectra and (B) nitrite concentrations of plasma-treated water treated for 30-150 min.

\section{Instrumental color measurements}

The lightness $\left(L^{*}\right)$, redness $\left(a^{*}\right)$, and yellowness $\left(b^{*}\right)$ of the cooked meat batters were measured using a spectrophotometer (CR-300; Minolta Inc., Japan). Measurements were taken at 3 different locations per sample, perpendicular to the surface of the cooked meat batter, with illumination area $30 \mathrm{~mm}$ in diameter.

\section{Statistical analysis}

This study was performed in three individual three replicates. The general linear model was constructed using raw data, and Tukey's multiple range test was used to evaluate significant differences $(p<0.05)$. Least square mean values and standard error of the least square means (SEM) are reported. SAS software (version 9.3, SAS Institute Inc., USA) was used for all statistical analyses.

\section{Results and Discussion}

\section{Nitrite concentration of PTW}

Increase in plasma treatment time resulted in increase of nitrite concentration in PTW (Fig. 2). After 30 min of plasma treatment, the concentrations of nitrite and nitrous acid in PTW were 46 ppm and 45 ppm, respectively. As nitrite combines with hydrogen atoms to form nitrous acid, resulting in nitrous acid being constantly broken down into nitrate and nitric oxide, PTW was used immediately after preparation for the curing process.

\section{Instrumental color of cooked meat batter}

Fig. 3 shows the typical color of cured meat developed in cooked meat batter treated with sodium nitrite or PTW. The $L^{*}$ and $b^{*}$ values of cooked meat batter treated with PTW or sodium nitrite were not significantly different from those of control (Table 2), as previously reported. Horsch et al. (2014) found that the $L^{*}$ value was not different between non-cured ham and ham cured with sodium nitrite. As expected, $a^{*}$ values of control was significantly lower than that of cooked meat batter cured with sodium nitrite or PTW $(p<0.05)$. The increase in $a^{*}$ value is a characteristic of meat cured with nitrite, regardless of the type of cured meat (de Oliveira et al., 2012; Horsch et al., 2014; Tsoukalas et al., 2011). Haldane (1901) demonstrated that addition of nitrite to meat batter resulted in the generation of nitric oxide, which subsequently produced nitrosylmyoglobin that imparts bright pink color to cured meat products after cooking. The $a^{*}$ values of cooked meat batter cured with PTW was significantly lower than that of coo-

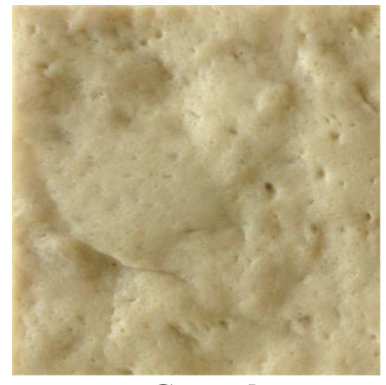

Control

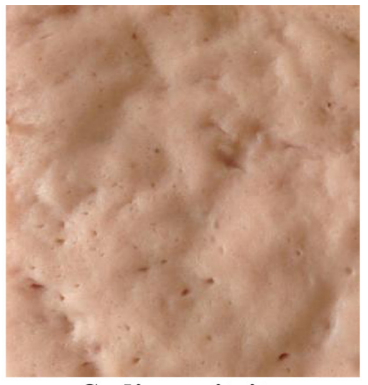

Sodium nitrite

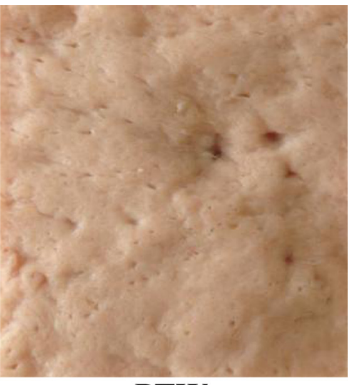

PTW

Fig. 3. The color of cooked meat batter. Control, non-cured meat batter; Sodium nitrite, meat batter cured with sodium nitrite; PTW, meat batter cured with plasma-treated water. 
Table 2. Instrumental color $\left(L^{*}, a^{*}\right.$, and $\left.b^{*}\right)$ of cooked meat batter

\begin{tabular}{ccccc}
\hline \hline & Control & Sodium nitrite & PTW & SEM $^{1}$ \\
\hline$L^{*}$ & 67.9 & 67.0 & 67.5 & 0.43 \\
$a^{*}$ & $2.0^{\text {c }}$ & $10.4^{\mathrm{a}}$ & $7.8^{\mathrm{b}}$ & 0.29 \\
$b^{*}$ & 10.4 & 9.0 & 9.6 & 0.43 \\
\hline
\end{tabular}

${ }^{1}$ Standard errors of mean $(n=9)$.

${ }^{a-c}$ Different letters within same row differ significantly $(p<0.05)$.

ked meat batter cured with sodium nitrite $(p<0.05)$, owing to lower concentration of nitrite in the former. The PTW used in this study contained $46 \mathrm{ppm}$ nitrite. Therefore, the nitrite in meat batter cured using PTW was 9.2 ppm while that in meat batter cured using sodium nitrite was $70 \mathrm{ppm}$. The increase in $a^{*}$ values of cured ham as a consequence of increase in nitrite concentration, has been previously reported (Horsch et al., 2014).

Thus, the cured color of cooked meat batter can be developed using PTW and it can be used as a nitrite source for curing, as an alternative to sodium nitrite. However, the plasma treatment system has to be improved to increase nitrite concentration in water. In addition, PTW can neither be distinctly classified as a synthetic nor a natural source of nitrite. Plasma treatment has previously been confirmed to be a safe water purification method (Foster et al., 2012). Therefore, our work suggests that PTW is a potential nitrite source that can be used in meat curing; however, further studies are warranted to improve the quality of a PTW-mediated curing process.

\section{Acknowledgements}

The work was supported by R\&D Program of 'Plasma Advanced Technology for Agriculture and Food (Plasma Farming, Project No. EN1425-1)' through the National Fusion Research Institute of Korea (NFRI) funded by the Government funds and Institute of Green Bio Science and Technology, Seoul National University.

\section{References}

1. Bogaerts, A., Neyts, E., Gijbels, R., and van der Mullen, J. (2002) Gas discharge plasmas and their applications. Spectrochim. Acta B 57, 609-658.

2. de Oliveira, T. L. C., de Carvalho, S. M., Soares, R. D., Andrade, M. A., Cardoso, M. D., Ramos, E. M., and Piccoli, R. H. (2012) Antioxidant effects of Satureja montana L. essential oil on TBARS and color of mortadella-type sausages formulated with different levels of sodium nitrite. LWT-Food Sci. Technol. 45, 204-212.

3. Foster, J., Sommers, B. S., Gucker, S. N., Blankson, I. M., and Adamovsky, G. (2012) Perspectives on the interaction of plasmas with liquid water for water purification. IEEE Trans. Plasma Sci. 40, 1311-1323.

4. Haldane, J. (1901) The red colour of salted meat. J. Hyg. 1, 115-122.

5. Horsch, A. M., Sebranek, J. G., Dickson, J. S., Niebuhr, S. E., Larson, E. M., Lavieri, N. A., Ruther, B. L., and Wilson, L. A. (2014) The effect of $\mathrm{pH}$ and nitrite concentration on the antimicrobial impact of celery juice concentrate compared with conventional sodium nitrite on Listeria monocytogenes. Meat Sci. 96, 400-407.

6. Krishnan, K. S. and Guha, A. C. (1934) The absorption spectra of nitrates and nitrites in relation to their photo-dissociation. Proceedings of the Indian Academy of Sciences-Section A, 1, 242-249.

7. Oehmigen, K., Hahnel, M., Brandenburg, R., Wilke, C., Weltmann, K. D., and von Woedtke, T. (2010) The role of acidification for antimicrobial activity of atmospheric pressure plasma in liquids. Plasma Process Polym. 7, 250-257.

8. Pegg, R. B. and Shahidi, F. (2000) Nitrite curing of meat: The $N$-nitrosamine problem and nitrite alternatives. Trumbull, CT: Food \& Nutrition Press, Inc.

9. Riordan, E., Minogue, N., Healy, D. A., and Sodeau, J. R. (2005) Spectroscopic and optimization modeling study of nitrous acid and aqueous solution. J. Phys. Chem. A 109, 779-786.

10. Sakiyama, Y., Graves, D. B., Chang, H. W., Shimizu, T., and Morfill, G. E. (2012). Plasma chemistry model of surface microdischarge in humid air and dynamics of reactive neutral species. J. Phys. D: Appl. Phys. 45, 425201 (19pp)

11. Sebranek, J. G. and Bacus, J. (2007) Natural and organic cured meat products: Regulatory, manufacturing, marketing, quality, and safety issues. American Meat Science Association white paper series, no. 1.

12. Sebranek, J. G., Jackson-Davis, A. L., Myers, K. L., and Lavieri, N. A. (2012) Beyond celery and starter culture: Advances in natural/organic curing processes in the United States. Meat Sci. 92, 267-273.

13. Sindelar, J. J., Cordray, J. C., Sebranek, J. G., Love, J. A., and Ahn, D. U. (2007) Effects of varying levels of vegetable juice powder and incubation time on color, residual nitrate and nitrite, pigment, $\mathrm{pH}$, and trained sensory attributes of ready-toeat uncured ham. J Food Sci. 72, S388-S395.

14. Song, H. P., Kim, B., Choe, J. H., Jung, S., Moon, S. Y., Choe, W., and Jo, C. (2009) Evaluation of atmospheric pressure plasma to improve the safety of sliced cheese and ham inoculated by 3 -strain cocktail Listeria monocytogenes. Food Microbiol. 26, 432-436.

15. Tsoukalas, D. S., Katsanidis, E., Marantidou, S., and Bloukas, J. G. (2011) Effect of freeze-dried leek powder (FDLP) and nitrite level on processing and quality characteristics of fermented sausages. Meat Sci. 87, 140-145.

16. Yong, H. I., Kim, H. J., Park, S., Alahakoon, A. U., Kim, K., Choe, W., and Jo, C. (2015) Evaluation of pathogen inactivation on sliced cheese induced by encapsulated atmospheric pressure dielectric barrier discharge plasma. Food Microbiol. 46, 46-50. 